\title{
Fotossíntese e Respiração Aeróbica: vamos quebrar a cabeça? \\ Proposta de jogo
}

Photosynthesis and Aerobic Respiration: Let's break head? Proposal for a game

\author{
Luciana Maria de Jesus Baptista Gomes ${ }^{1 *}$, Jorge Cardoso Messeder ${ }^{2}$ \\ ${ }^{1}$ Secretaria de Estado de Educação do Rio de Janeiro - SEEDUC-RJ \\ ${ }^{2}$ Instituto Federal de Ciência, Educação e Tecnologia do Rio de Janeiro - IFRJ - campus Nilópolis \\ *e.mail: lucianajbg@yahoo.com.br
}

\section{Resumo}

A fotossíntese e a respiração celular aeróbica são dois processos metabólicos que compõem o conteúdo programático de Ciências e de Biologia, da Educação Básica brasileira, modalidade regular. No entanto, são constatadas dificuldades para o entendimento destes fenômenos porque exigem raciocínio abstrato e um suporte de conceitos científicos. Assim, para facilitar a aprendizagem, foi elaborado o jogo "Fotossíntese e Respiração Aeróbica: Vamos quebrar a cabeça?". O professor age com intencionalidade, por meio da problematização. A vantagem deste jogo é que pode ser utilizado desde as aulas de Ciências do $6^{\circ}$ ano do Ensino Fundamental até as de Biologia do Ensino Médio. Outra vantagem é que pode ser produzido tanto pelo professor quanto pelo aluno. Ao ser utilizado pelos alunos, o jogo demonstrou ser promissor na sala de aula, pois proporciona mais uma oportunidade de desenvolvimento do ser humano integral em suas múltiplas vertentes que são inerentes a cada um.

Palavras-chave: fotossíntese; jogo; respiração celular aeróbica.

\section{Abstract}

Photosynthesis and aerobic cellular respiration are two metabolic processes that make up the curriculum of Science and Biology, Brazilian Basic Education, regular mode. However, difficulties are found for the understanding of these phenomena because they require abstract reasoning and support of scientific concepts. Thus, to facilitate learning, the game "Photosynthesis and Aerobic Respiration: Let's break head?" was elaborated. The teacher acts with intentionality, through questioning. The advantage of this game is that it can be used from the lessons of Sciences of the 6th year of Elementary School up to High School Biology. Another advantage is that it can be produced by both the teacher and the student. When be used by students, the game has shown promise in the classroom, it provides another opportunity to develop the whole human being in its multiple aspects that are inherent to each.

Keywords: photosynthesis; game; aerobic cellular respiration. 


\section{Ficha da atividade desenvolvida}

Título: Fotossíntese e Respiração Aeróbica: Vamos quebrar a cabeça? Proposta de jogo Público alvo: alunos dos $6^{\circ}$ anos do Ensino Fundamental até a $1^{1}$ série do Ensino Médio Disciplinas relacionadas: Biologia, Ciências e Química da Educação Básica

\section{Objetivos educacionais:}

- compreender os processos de fotossíntese e de respiração aeróbica como processos biológicos, ou seja, que ocorrem nos seres vivos;

- citar as substâncias utilizadas e as formadas em cada processo;

- associar os nomes das substâncias às suas fórmulas químicas;

- perceber a relação de consumo e de síntese destas substâncias em cada processo;

- montar as equações químicas de cada processo;

- classificar os seres vivos disponíveis no jogo como autótrofos ou heterótrofos.

Justificativa de uso: Dificuldades percebidas, por anos de prática docente, dos alunos perceberem a relação entre os processos bioquímicos envolvidos e determinar quais os seres vivos realizam estes processos.

Conteúdos trabalhados: Metabolismo energético da fotossíntese e da respiração aeróbica, fórmulas químicas, equação química, seres vivos autótrofos e seres vivos heterótrofos.

Materiais utilizados: tabuleiro formado por duas placas galvanizadas, ficha "Regras do Jogo", "Texto Inicial", fichas coloridas imantadas, imãs de geladeira de diferentes seres vivos e "Ficha Final". 


\section{Introdução}

Bioquímica é um assunto que, na Educação Básica no Brasil, permeia as disciplinas de Ciências no Ensino Fundamental e de Biologia no Ensino Médio, não aparecendo, no ensino regular anual, como uma disciplina isolada das demais. Desta forma, seus conceitos são evocados para explicar muitos fenômenos observados na natureza - como por exemplos, a manutenção das quantidades dos gases dióxido de carbono e oxigênio na atmosfera e a produção de energia pelos seres vivos.

Entretanto, o entendimento dos processos bioquímicos, como o da fotossíntese e o da respiração aeróbica envolvem conceitos abstratos que exigem conhecimentos científicos de duas áreas - Biologia e Química. A exigência de um alto nível de abstração associada com a nomenclatura específica dificulta a compreensão destes eventos e a relação existente entre os mesmos, caracterizando como um assunto de maior dificuldade, tal como ocorre com o ensino de Química [1]. Sem a compreensão adequada, o aluno pode partir para a atitude de decorar termos que não Ihe fazem sentido, não ocorrendo a contextualização e a percepção de que tais fenômenos estão presentes em seu cotidiano; assim, não colabora efetivamente para sua aprendizagem [2-3].

Para diminuir a dificuldade pontuada, dentre os diversos materiais didáticos, os jogos podem ser utilizados como auxiliares dos alunos que, por meio da reflexão e do raciocínio próprio, reforçam o assunto facilitando a compreensão dos conceitos científicos abstratos [4-5]. Os jogos também promovem a interação entre os alunos, beneficiando a socialização e o fortalecimento de laços afetivos na turma que corroboram com seu desenvolvimento social [6-7].

\section{Procedimentos e recursos}

O jogo pode ser utilizado por um a cinco alunos e é composto por: um tabuleiro retangular metálico; uma ficha "Regras do Jogo"; um "Texto Inicial"; fichas coloridas imantadas distribuídas da seguinte forma: duas fichas escritas "gás carbônico", três "água", duas "gás oxigênio", duas "glicose", uma "energia", uma "luz", uma "clorofila", duas fichas em forma de seta $(\leftarrow)$, seis fichas com forma de sinal de adição $(+)$, duas fichas " $\mathrm{CO}_{2}$ ", três fichas " $\mathrm{H}_{2} \mathrm{O}$ ", duas fichas " $\mathrm{O}_{2}$ " e duas " $\mathrm{C}_{6} \mathrm{H}_{12} \mathrm{O}_{6}$ "; imãs (tipo usado em porta de geladeira) de diferentes seres vivos e uma "Ficha Final". As imagens deste material estão reunidas na seção Apêndice. 
REB na Escola: Fotossíntese e Respiração Aeróbica: vamos quebrar a cabeça? Proposta de jogo

O tabuleiro é composto por duas chapas galvanizadas, adquiridas em estabelecimentos que compram sucata, como papel, papelão e metais oriundos de latas de refrigerantes e grades de janelas entre outros (na cidade do Rio de Janeiro, estes locais recebem o nome de "ferro-velho").

Com o auxílio de um serralheiro, as placas compradas foram recortadas em pedaços com dimensões $30 \mathrm{~cm}$ por $13 \mathrm{~cm}$. Duas dessas partes são unidas pelo lado menor $(13 \mathrm{~cm})$, com uma fita adesiva específica, permitindo que o tabuleiro seja fechado como um livro, o que facilita o transporte. O verso do tabuleiro foi revestido com papel adesivo decorado da marca Contact $®$, unindo as duas partes e configurando o aspecto estético. As bordas das chapas foram revestidas por fita isolante na cor preta, protegendo as mãos contra possíveis cortes.

No tabuleiro, na face onde efetivamente ocorre o jogo, há duas regiões demarcadas, com nomes escritos manualmente com caneta Marcador Permanente CDDVD, na cor preta: a maior é a "Respiração Aeróbica" e a menor que está inserida dentro anterior e é delimitada por uma fita adesiva verde, é a região da "Fotossíntese". A configuração foi assim executada para que ajude o aluno a visualizar, intuitivamente, ao final do jogo, que os seres vivos que fazem fotossíntese também respiram, mas que existem alguns seres vivos que apenas respiram. Recorre-se, portanto à noção de conjunto, em Matemática, que já é trabalhada com os alunos ainda no primeiro segmento do Ensino Fundamental. As imagens do tabuleiro e dos componentes do jogo estão reunidas no Apêndice $A$.

A ficha "Regras do jogo" (Apêndice B) e o "Texto Inicial" (Apêndice C) foram confeccionados no computador em papel cartão, tamanho A4 em orientação paisagem. Para conferir uma maior durabilidade, ambos foram encapados com papel adesivo Contact $®$ transparente.

As fichas foram confeccionadas no computador, em folhas brancas de papel A4, em cores diferentes para que o aluno possa identificar os nomes das substâncias às suas fórmulas químicas. Por exemplo, a substância "água" foi confeccionada na cor azul-claro, que é a mesma da fórmula " $\mathrm{H}_{2} \mathrm{O}$ ".

Todas as fichas, as setas e os sinais de adição foram colados em folhas imantadas adesivadas, o mesmo tipo utilizado para criar imãs comerciais, para que pudessem, durante o jogo, ficar aderidos ao tabuleiro. Essas fichas também foram encapadas, na face onde estão expostos os nomes, as fórmulas e os sinais de adição e 


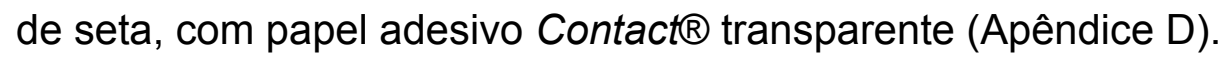

A Ficha Final, em folha de ofício branca, tamanho A4 foi confeccionada em computador e o quantitativo é de uma ficha por aluno. As perguntas estão relacionadas no Apêndice $\mathrm{E}$.

As figuras que representam os seres vivos são denominadas "imãs de geladeira" e foram compradas em loja que vende utensílios para casa.

As regras do jogo estão descriminadas a seguir:

$1^{\circ}$ Escolha uma pessoa do seu grupo para ser o leitor do Texto Inicial. Neste texto, há pistas sobre como ocorrem a fotossíntese e a respiração aeróbica.

$2^{\circ}$ Primeiro desafio: Com as fichas das palavras, as setas e os sinais de adição, o grupo deve montar os processos de fotossíntese e de respiração aeróbica nos espaços indicados.

$3^{\circ}$ No espaço da "Respiração Aeróbica" coloque uma seta no meio. Ao lado esquerdo da seta, coloque as substâncias utilizadas; para separar as substâncias, acrescente os sinais de adição que forem necessários. Ao lado direito da seta, coloque as substâncias formadas e entre cada substância os sinais de adição.

$4^{\circ}$ O espaço menor é o da "Fotossíntese". A seta se posiciona no meio deste espaço e o procedimento é o mesmo: ao lado esquerdo da seta coloque as substâncias utilizadas no processo e ao lado direito, as substâncias formadas. Utilize os sinais de adição para separar as substâncias.

$5^{\circ}$ Segundo desafio: o grupo deve associar as fórmulas das substâncias com seus nomes. Existe uma pista para facilitar... Pense e descubra!

$6^{\circ}$ Terceiro desafio: o Texto Inicial se refere aos seres vivos que realizam somente a respiração aeróbica e os seres vivos que realizam a respiração aeróbica e a fotossíntese. Coloque os seres vivos com imãs nos espaços correspondentes.

$7^{\circ}$ Desafio final: individualmente, preencha a Ficha Final e entregue ao professor.

\section{Desenvolvimento da atividade}

A atividade descrita a seguir ocorreu em duas turmas de $7^{\circ}$ ano do Ensino Fundamental, em uma escola de esfera pública do município de Nilópolis, no estado do Rio de Janeiro, com alunos com idades entre 12 e 14 anos. A escola é em área urbana, atendendo a muitos alunos que são assistidos por algum programa assistencial 
governamental, caracterizando um público de classe baixa.

A atividade aconteceu na sala de aula, equipada com mesas, cadeiras e um quadro branco: inicialmente a professora-autora realizou um levantamento das concepções prévias dos alunos, com perguntas sobre o que os alunos se lembravam dos dois processos; à medida que eles lembravam e falavam, tudo foi escrito no quadro para que os alunos pudessem ler e participar. Também foram realizadas perguntas pela professora para motivar ainda mais a conversa sobre a fotossíntese e a respiração celular aeróbica.

Passada esta etapa, a professora propôs o jogo e a divisão dos alunos em grupos de, no máximo, cinco alunos escolhidos por eles mesmos, reafirmando uma postura proativa dos próprios alunos quanto à formação dos grupos, reforçando a autonomia e também os laços de amizade.

Como a própria dinâmica do jogo requer arrumação dos alunos em grupos e a organização do próprio grupo para jogar, por experiência de aplicação, sempre ocorre uma excitação inicial dos alunos, principalmente ao manusear os imãs dos seres vivos. Portanto, até que se concentrem em realizar efetivamente o jogo, o tempo suficiente para a realização da atividade é de cem minutos.

Apresentam-se na figura a seguir imagens captadas durante a realização do jogo em uma das turmas de $7^{\circ}$ ano do Ensino Fundamental.

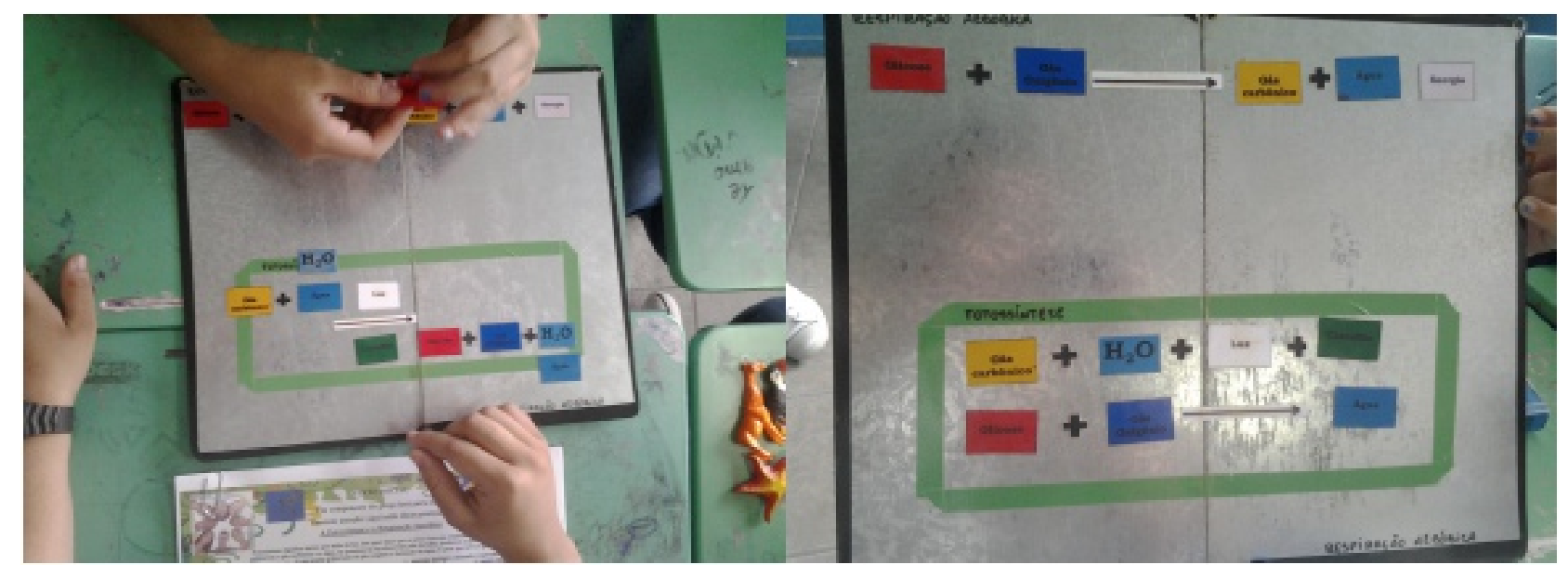

Figura 1. Alunos cumprindo a primeira etapa do jogo - a montagem das equações químicas da respiração aeróbica e da fotossíntese. 
REB na Escola: Fotossíntese e Respiração Aeróbica: vamos quebrar a cabeça? Proposta de jogo

\section{Resultados esperados}

Este jogo foi aplicado nas aulas de Ciências em turmas do $7^{\circ}$ ano do Ensino Fundamental (EF) e nas aulas de Biologia em turmas dos $1^{\circ}$ e $2^{\circ}$ anos do Ensino Médio (EM), em escolas públicas das esferas municipal e estadual do Rio de Janeiro, como uma etapa conclusiva sobre a classificação dos seres vivos em heterótrofos e autótrofos e, no Ensino Médio, em etapa conclusiva sobre metabolismo energético e diferenciação entre os seres vivos.

Em turmas do Ensino Fundamental (EF), os alunos concordam em participar, mas 0 ato de jogar tende a ser mais desordenado, pois querem mexer com as peças, principalmente com os imãs de geladeira dos seres vivos. Já os alunos do Ensino Médio (EM) também demonstram interesse em jogar e tendem a ser mais organizados na participação. Infere-se aqui a diferença da maturidade psicológica entre os alunos, pois, se no EF eles são, em sua maioria, pré-adolescentes, no EM já são adolescentes com idades acima dos 15 anos. Ainda assim, percebe-se um grande envolvimento dos alunos para participar do jogo, pois a ludicidade torna a aula mais dinâmica e motivadora.

Ao transpor os conceitos científicos da fotossíntese e da respiração aeróbica, que estão no campo abstrato do pensamento, para os materiais concretos - como o tabuleiro e as fichas -, esta concretude auxilia a compreensão e apropriação destes conceitos que estão presentes no conteúdo programático das Ciências e da Biologia, pois se tornam algo materializado e "palpável", facilitando o entendimento para os alunos que ainda estão em pleno desenvolvimento do pensamento abstrato, segundo Piaget [7].

$\mathrm{O}$ ato de jogar é um processo ativo entre os alunos e compromete o ensino de Ciências para que efetivamente passe pela investigação, questionamento e problematização, tornando o aluno também ativo em seu processo de aprendizagem. Por exemplo, na conversa inicial com a professora - a que ocorreu antes mesmo da distribuição do jogo - os alunos são convidados a responderem sobre assunto que já conheciam, trazendo à lembrança os nomes das substâncias envolvidas e dos seres vivos que realizavam os processos metabólicos.

Por esses cinco anos de aplicação do jogo, dependendo do ano letivo e do domínio cognitivo do participante, pode ocorrer uma dificuldade inicial de interpretação do texto Inicial: assim, alguns alunos demonstraram pouco conhecimento de algumas palavras do texto, necessitando da ajuda dos colegas e também da professora para 
REB na Escola: Fotossíntese e Respiração Aeróbica: vamos quebrar a cabeça? Proposta de jogo

interpretarem o mesmo. O benefício de estar em grupos pequenos, de amigos, é que os alunos se sentem à vontade para perguntar suas dúvidas sem se sentirem constrangidos.

Nas turmas de $7^{\circ}$ ano do Ensino Fundamental, ainda ocorreram algumas tentativas de chacota entre os alunos, mas tais situações tiveram intervenção pela professora, com o discurso de que estamos todos aprendendo a vida inteira e de que é atitude de coragem o aluno esclarecer sua dúvida na escola.

Outra dificuldade percebida foi a transposição do que é lido pelos alunos, no domínio da Língua Portuguesa, para a linguagem utilizada em Biologia e Química, que é a representação em equações químicas dos dois processos. A intervenção da professora foi fundamental para ajudar a montagem das equações químicas.

Alguns alunos do $7^{\circ}$ ano do EF perceberam a disposição do espaço da "Fotossíntese" estar dentro do espaço da "Respiração Aeróbica" e conseguiram entender a exclusividade de uma parte dos seres vivos que realizam apenas a respiração aeróbica. Tal fato foi compartilhado entre os colegas de sala e, mesmo não fazendo parte dos objetivos do jogo, a noção de conjunto que é discutida em Matemática transpareceu.

$\mathrm{Na}$ etapa de classificar os seres vivos, se são autótrofos ou heterótrofos, os grupos a quem o jogo foi utilizado para esta pesquisa, classificaram erroneamente "fungo" como "ser vivo que faz fotossíntese". Indagados porque seria assim, a resposta foi a de que "parecia mais com uma planta do que com um animal". Tal resposta faz repensar como um conceito prévio equivocado se torna mais arraigado muitas vezes do que um conceito científico "imposto" pela educação escolar, pois o grupo dos fungos é estudado desde $05^{\circ}$ ano do Ensino Fundamental e novamente discutido no $7^{\circ}$ ano desta mesma modalidade de ensino. Contudo, o conceito prévio e empírico, prevalece sobre a classificação científica estudada.

Ocorre desta forma, uma não-apropriação da cultura escolar, ora pela própria postura "narrativa-contemplativa" da escola [8] - onde o professor apenas fala e os alunos, contemplam - ora pela postura do aluno, que tem o direito de se apropriar ou não dos conceitos que a escola lhe apresenta e que ele acha conveniente, pois ele, reconhecidamente, é agente do seu próprio processo de aprendizagem [9].

O jogo proporcionou momentos de reflexão e discussão, com condução da professora, por meio de perguntas e problematização com os grupos de alunos: assim, por meio de características comparativas entre os seres vivos, os alunos concluíram corretmente a classificação dos fungos como heterótrofos, principalmente pela ausência 
do pigmento clorofila, o que os torna, neste critério, mais semelhantes aos animais.

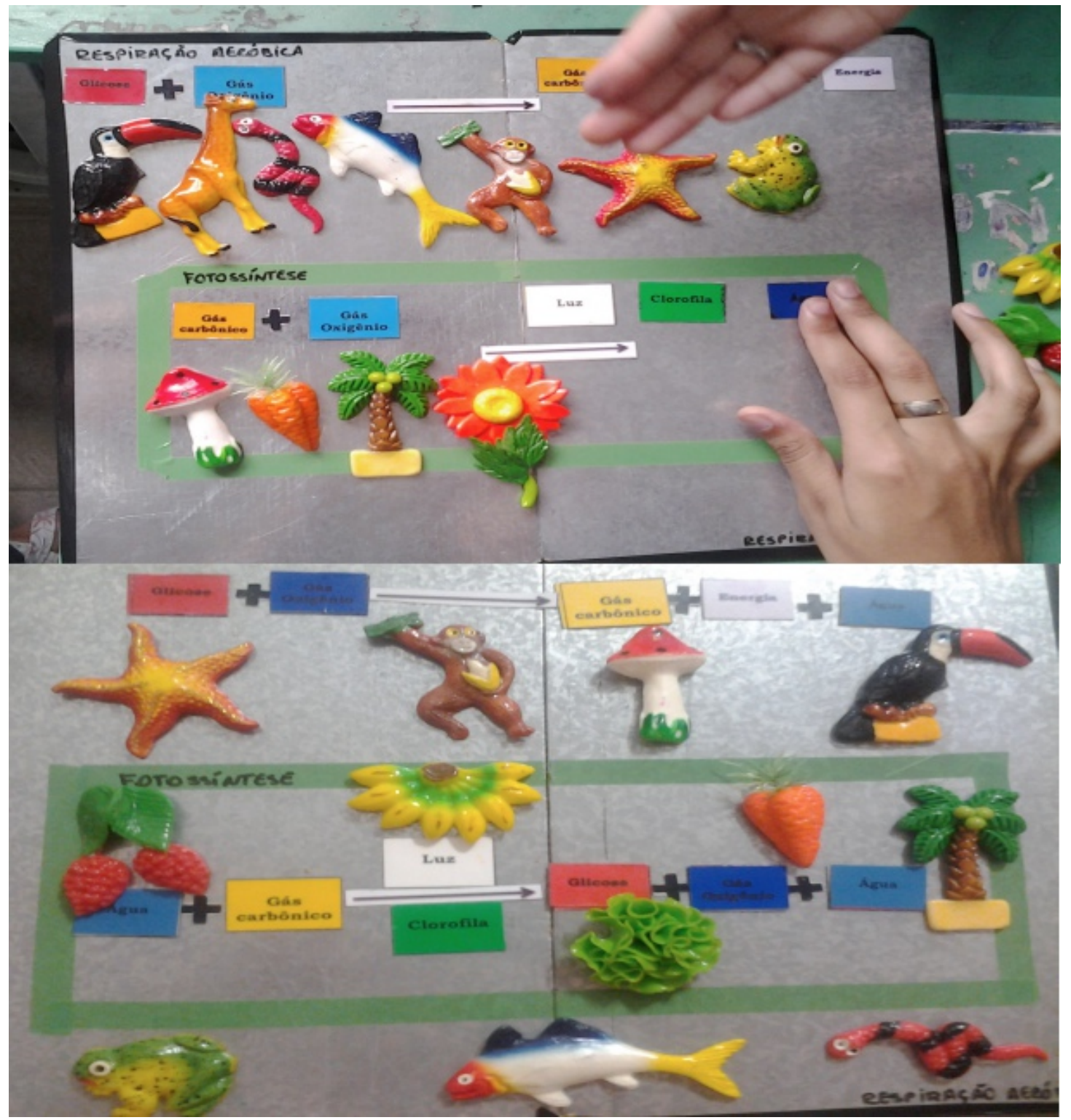

Figura 2. Jogo concluído. Percebe-se que, na primeira imagem, de cima para baixo, fungo está classificado como ser vivo que realiza respiração aeróbica e também fotossíntese (no espaço da "Fotossíntese"), gás oxigênio aparece como reagente na equação da fotossíntese e clorofila como produto. Após um diálogo investigativo com a professora, comparando os dois processos, por meio da leitura do Texto Inicial e as características dos vegetais e dos animais, os alunos perceberam o equívoco e, de maneira correta, refizeram o jogo.

\section{Impacto no ensino-aprendizado}

A participação no jogo gera tomada de decisões por parte do aluno e de seu grupo e todo o processo do ato de jogar passa pelas etapas de escutar o outro e, por meio de argumentos, decidir o que deve ser feito. Assim, permeando a interpretação do texto com a opinião de cada componente do grupo, percebeu-se a construção de uma rede de negociação por meio da comunicação oral, com os alunos ora convencendo ora 
REB na Escola: Fotossíntese e Respiração Aeróbica: vamos quebrar a cabeça? Proposta de jogo

acatando a decisão da maioria do grupo, até chegar ao que seria a resposta da equipe no tabuleiro.

No entanto, a situação descrita no tópico anterior - a respeito da classificação equivocada do fungo com um ser vivo que realiza fotossíntese - só foi contornada quando a professora, de grupo em grupo de alunos, pôde conversar e levantar questões problematizadoras (como "se o fungo faz fotossíntese, como ele se desenvolve em ambientes sem luz?" e "que pigmento é importante para a absorção da luz? O fungo tem esse pigmento?"), fazendo com que os alunos refletissem sobre suas próprias respostas e, reconhecido o equívoco, pudessem reclassificar o fungo.

Outro momento em que foi necessária a intervenção da professora em todos os grupos do $7^{\circ}$ ano do Ensino Fundamental foi o ato de associar os nomes às fórmulas químicas correspondentes, pois os alunos desconheciam as mesmas. A única exceção foi a fórmula da água $\left(\mathrm{H}_{2} \mathrm{O}\right)$ que os alunos conheciam.

$\mathrm{O}$ ato de jogar também necessita de um determinado ordenamento proposto pelas regras e foi perceptível em alguns grupos a impaciência em lê-las e se organizarem tal qual foi proposto. Novamente, passada a euforia e a desconcentração, estes mesmos grupos conseguiram terminar o jogo. Desta forma, o jogo se torna um exercício de convivência social, reforçando os laços de relacionamento e de afeto entre professor e alunos e entre os próprios alunos, caminhando no campo das relações sociais estabelecidas em sala de aula, além de facilitar a apreensão dos conteúdos científicos propostos. Assim, estas relações sociais proporcionadas pelo jogo são instrumentos de aprendizagem para o aluno muito além do conteúdo programático [10].

\section{Conclusões}

Esse jogo é produzido com material de fácil acesso e de baixo custo, podendo ser montado pelo professor ou então, se houver mais tempo para o projeto, produzido pelos próprios alunos. Pode ser utilizado desde as aulas de Ciências do $6^{\circ}$ ano do Ensino Fundamental até as de Biologia do Ensino Médio, em diversos momentos, como a comparação dos gases oxigênio e dióxido de carbono na atmosfera, a comparação entre organismos autótrofos e heterótrofos, entre outros.

O professor precisa pensar e assumir sua prática pedagógica, agindo na sala de aula com intencionalidade pedagógica, agindo a partir de objetivos previamente definidos 
[11]. Por exemplo, para tornar o ato de jogar mais interessante e dinâmico, a estratégia adotada foi a proposta de uma discussão inicial, para que os alunos se motivassem a responder aquilo que eles lembravam sobre fotossíntese e respiração aeróbica, ocorrendo uma valorização e conhecimento das concepções prévias dos estudantes. Durante o jogo, a proposta foi a de circular por entre os grupos, com atenção aos procedimentos realizados pelos alunos. Quando ocorria alguma dificuldade ou equívoco, a postura adotada pela professora foi a da problematização, ou seja, por meio de perguntas e situações, os alunos refletiam sobre o que haviam feito e eles mesmos rearrumavam as peças no tabuleiro.

O professor precisa também ser flexível e estar preparado para intervir, numa postura dialógica, situações que interfiram o andamento considerado adequado para este momento pedagógico.

A alfabetização científica é importante para que o aluno consiga dominar e compreender as formas que Biologia, Ciências e Química utilizam ao escrever seus conhecimentos. E o jogo proporciona este conhecimento, durante as etapas do jogo: primeiramente, os alunos montam as duas equações químicas representativas dos processos da fotossíntese e da respiração aeróbica e numa etapa subsequente, associam os nomes das substâncias com suas fórmulas químicas. Compreendendo estas formas de linguagem, o aluno tem a oportunidade de perceber as conexões existentes entre as diversas áreas do conhecimento, o que o auxilia em sua construção de uma percepção da realidade mais complexa e sistêmica. Habilitado pelo conhecimento científico apreendido, o aluno pode entender e inferir em seu derredor ao qual está imerso, com reflexões e argumentações e intervém em sua realidade.

Assim, os alunos exercitam conceitos científicos e também os aspectos emocionais e sociais que compõem cada pessoa. Esses aspectos foram manifestos e percebidas as relações sociais estabelecidas em suas nuances: os conflitos de opiniões e as relações de poder entre os participantes de uma mesma equipe. Em um dos grupos ficou nítida a postura autoritária de dois alunos, que apresentaram dificuldade em parar para ouvir o outro jogador. Coube à professora intervir com sabedoria e tranquilidade, conversando diretamente com os dois alunos, para reorganizar esta relação social e erradicar tal postura que acabava por prejudicar principalmente a convivência social dos jogadores.

Portanto, o jogo "Fotossíntese e Respiração Aeróbica: vamos quebrar a cabeça?" 
REB na Escola: Fotossíntese e Respiração Aeróbica: vamos quebrar a cabeça? Proposta de jogo

demonstrou ser promissor na sala de aula, pois proporciona mais uma oportunidade de desenvolvimento do ser humano integral em suas múltiplas vertentes que são inerentes a cada um.

\section{Referências}

[1] Özmen H. Some student misconceptions in chemistry: A literature review of chemical bonding. Journal of Science Education and Technology 2004; 1(2):147-159.

[2] Gomes LMJB, Gouveia, DSM. Há química no meio do caminho, no meio do caminho há química. Apresentação oral do XI Simpósio de Profissionais de Ensino de Química do GPQuAE - Grupo de Pesquisas em Química Analítica e Educação- GPQuAE.; 26 e 27 de outubro de 2012, Campinas, SP. Acesso em 14 de fevereiro de 2013. Disponível em: http://gpquae.iqm.unicamp.br/lisTrabalhosSIMPEQ11.pdf.

[3] Krasilchik M, Marandino M. Ensino de Ciências e Cidadania - 2.ed. - São Paulo : Moderna, 2007.

[4] Cardona TS. Modelos pedagógicos e novas tecnologias: jogos e imagens. Terceiro colóquio Internacional sobre Epistemologia e Pedagogia das Ciências. 2007. Acesso em 6 out . 2011. Disponível e m: http://www.dctc.pucrio.br/prof.com.ciencia/CIEPAC/2007/TaniaSilveiraJogoselmagens.pdf.

[5] Krasilchik M. Práticas do ensino de biologia. 4. ed. São Paulo: EDUSP; 2004.

[6] Carneiro CDR, Lopes OR. Jogos didáticos como instrumentos facilitadores do ensino de geociências: O jogo sobre "ciclo das rochas". Acesso em 14 de fevereiro de 2013. D i s p o n íve I http://www.ige.unicamp.br/simposioensino/simposioensino2007/artigos/009.pdf

[7] Piaget J. A psicologia da criança. Ed. Rio de Janeiro: Bertrand Brasil, 1998.

[8] Martín Gordillo M. EL enfoque CTS y la educación sobre las TIC. Buenos Aires, IBERTIC, 2012. Acesso em 15 de março de 2013. Disponível em: https://.youtube.com/watch?v=IT1iD4DdXs.

[9] Barbosa, ACR. O ensino por competências e a formação docente para o ensino militar: contribuições para a Educação Sociocomunitária. Revista de Ciências da Educação 2012; 14(27): 151-164.

[10] Saviani D. Educação: do senso comum à consciência filosófica. 17. ed. Campinas, SP: Autores Associados, 2007.

[11] Vygostsky L. A formação social da mente. São Paulo: Martins Fontes, 1998.

\section{Agradecimentos}

Aos alunos que jogaram "Fotossíntese e Respiração Aeróbica: Vamos quebrar a cabeça?". 
Apêndice A. Material componente do jogo: Tabuleiro, peças do jogo, imagens de seres vivos e Ficha Final (imagens sem escala)
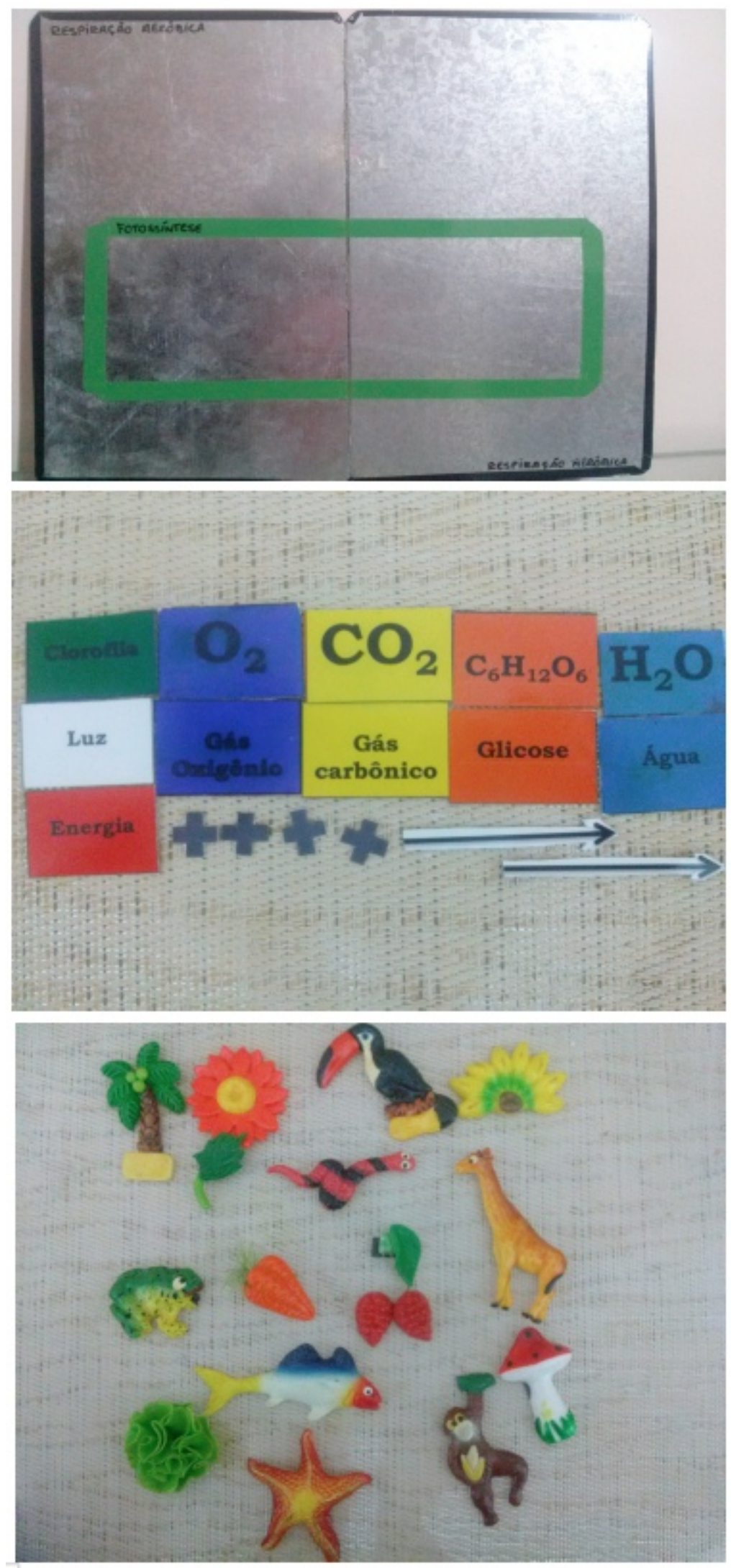


\section{Apêndice B. Material componente do jogo: Regras do Jogo}

A página com as regras foi impressa em papel cartão, tamanho $A 4$, em orientação paisagem e, para maior durabilidade, foi encapada com papel Contact $\circledast$ transparente.

\section{Regras do jogo:}

Escolha um do seu grupo para ser o leitor do Texto Inicial. Neste texto, há pistas sobre como ocorrem a fotossíntese e a respiração aeróbica.

Primeiro desafio: Com as fichas das palavras, as setas e os sinais de adição, o grupo deve montar os processos de fotossíntese e de respiração aeróbica nos espaços indicados como "RESPIRAÇÃO AERÓBICA" e "FOTOSSÍNTESE".

No espaço da "Respiração Aeróbica", coloque uma seta no meio. Ao lado esquerdo da seta, coloque as substâncias utilizadas; para separar as substâncias, acrescente os sinais de adição que forem necessários. Ao lado direito da seta, coloque as substâncias formadas e entre cada substância os sinais de adição.

O espaço menor é o da "FOTOSSÍNTESE". A seta se posiciona no meio deste espaço e o procedimento é o mesmo: ao lado esquerdo da seta coloque as substâncias utilizadas no processo e ao lado direito, as substâncias formadas. Utilize os sinais de adição para separar as substâncias.

Segundo desafio: o grupo deve associar as fórmulas das substâncias com seus nomes. Existe uma pista para facilitar... Pense e descubra!

Terceiro desafio: o Texto Inicial se refere aos seres vivos que realizam somente a respiração aeróbica e os seres vivos que realizam a respiração aeróbica e a fotossíntese. Coloque os seres vivos com imãs nos espaços correspondentes.

Desafio final: individualmente, preencha a Ficha Final e entregue ao professor. 


\section{Apêndice C. Material componente do jogo: Texto Inicial}

Este Texto Inicial foi impresso em papel cartão, tamanho A4, em orientação paisagem e, para maior durabilidade, foi encapado com papel Contact $₫$ transparente.

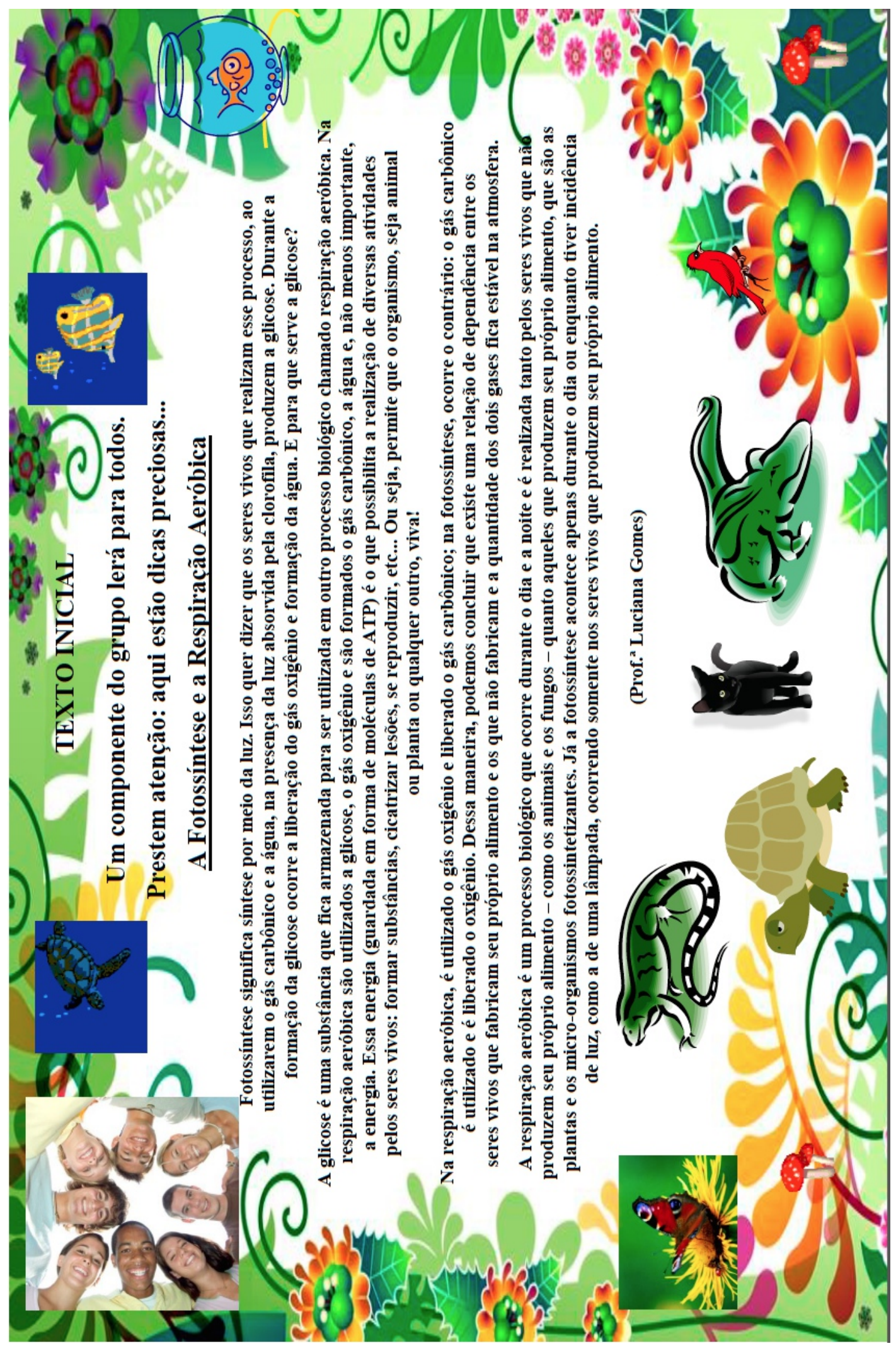




\section{Apêndice D. Material componente do jogo: Peças do jogo}

As fichas são impressas e depois, aderidas em folhas imantadas adesivadas. $\mathrm{O}$ quantitativo abaixo é suficiente para 1 jogo:

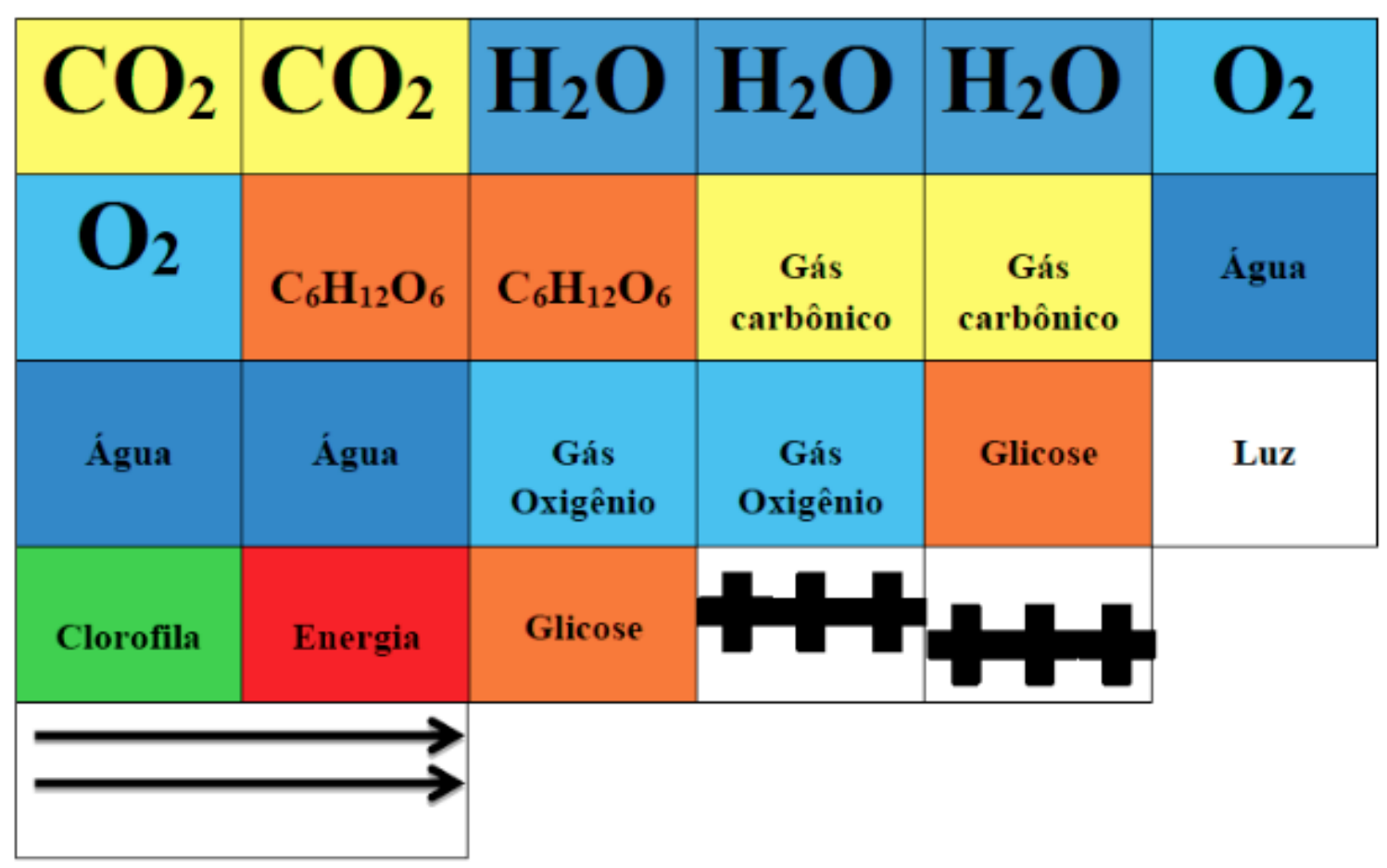




\section{Apêndice E. Material componente do jogo: Perguntas da Ficha Final}

Essas perguntas foram digitadas e impressas em folha tamanho A4, em orientação paisagem. Depois foi distribuída uma folha para cada aluno.

1- Que substâncias são utilizadas na respiração aeróbica?

2- Que substâncias são formadas na respiração aeróbica?

3- Que substâncias são utilizadas na fotossíntese?

4- Que substâncias são formadas na fotossíntese?

5- Complete:

a. Na respiração aeróbica é utilizado o gás e liberado o gás e é um processo que ocorre durante $o$ e a

b. Na fotossíntese ocorre o contrário: é utilizado o gás e liberado o gás e é um processo que ocorre apenas durante $o$ 